\title{
O Papel da Comunicac;áo na Gestáo de Crises
}

\section{Res umo}

A velocidade d.t comunica áo e a Jificuldade dos exr:arivos de resolve r os problemas acabam gerando crises de imagem que amea $m$ a reputa ao de pescosse orga niza óes. Além de colocar em risco o negócio e o futuro da empresa. A comunicao tem um papel decisivo na percep áo da sociedade em relat:áa 3s crises. Equivocadamente arribui-se a comunica áo a funt:áo de liderar cssc processo quando seu papel esr:ílimirado a promover e preservar a imagcm das organizat;:óes. A gesráo da crise de en volver todos os dirigenres da organiza áo e pressupiie preven o, gc:stáo de riscos, muit informaáo $e$ mapeamemo das vulncr:: bilidades

Palavras-chave: $1 \mathrm{~m}$ prensa, crises empresariais, adminimat :áo de criseco mu nicao organiz.acional. comunica áo e crise.

\section{ELPAPEL DE LA COIl<IUNICACIÚN EN LA GESTIÚN DE CRISIS}

$$
\text { Resumen }
$$

La velocidad de la com u nicación y la dificultad de los cjecurivos en resolver problemas acaban por generar crisis de imagen que a menazan la reputación de individuos y organizaciones, adcmí́s de poner en riecro el negocio)' el futur de la empresa. La comunicación tiene un papel decisivo en la percepción de la sociedad en relación a la crisis.

De manera eq uivocada se le atribu ye a l.t comu nicación la función de liderar ese proceso, cuando su rol se limit a a promover f' preservar la imagen de las organizaciones. La gcsrión de crisis debe ncluir a rodos los dirigentes de la organización y presu pone la prevención, gestión de: riesgos, abundame información y mapeo de las vulnerabilidades.

Palabras clave: Prensa, crisis empresarial, admi n ist ración de crisis, comu nicación org.mizacional, comunicación y crisis.

\section{THE COMIUNICATION ROLE IN CRISES MANAGEMENT} Abstraer

The speed of communicarion :uid the difllculty rhar execu tives experience when solving problems end up by generating : $u$ i im ge crises thar jeopardizes ind ividual and organizarional repuration, thus puuing $\cdot H$ risk business and rhe furure of rhe company. Communicar ion pb.ys a crucial role in rhe perception that sacie( $\bullet$ has in regards ro crisis.

Wrongfu lly, comm unicarion has been considered as rhe leader of such process, ahhough its role is limited ro promore and ro preserve the organizarions' image. Crisis managemcm musr include all leaders of rhe orga nizarían, :md requires prevenrion, risk managemem, lors of informution and mapping vulnerabilitics.

Key words: I'ress, enterprisc crisis, crisis managcrnenr, orga nizational communicarion, communical'́on and crisis.

\section{oao José Forni \\ Mestre em Comu nica;iao pela \\ Univers idade de Brasili.. MBA em}

Gestáo Estratégica pela Universidade de ao Paulo.

omi@rerracombr 
Costuma-se designar qualquer problema das organiza<;:óes como crise. Um equívoco, certamente. Crise é mais do que um problema. Mas desde 2008, a palavra acabou se incorporando ao jargáo empresa rial. Teima em náo sair das manchetes. Náo bastassem as crises rotineiras, envolve ndo governos e empresas, a tempestade que come<;::ou a varrer a economía O..- mundial, a partir de setembro daquele ano, trouxe a c rise definitivamente para as primeiras páginas.

Crise é uma ruptura na normalidade, que amea<;:a a reputa<;:áo e os negócios (Duarte: 2010). É um fato negativo que, na maior parte das vezes, escapa ao controle da empresa. A palavrinha que incomoda e denota uma situa<;:áo de perigo, pairando sobre as organiza<;:óes, se tornou também obrigatória no repertório dos artigos e compendios adm inistrativos e económ icos. Por isso, a gestáo de crises passa a ser competencia cada vez mais exigida dos administradores. Nesse contexto, o papel da mídia também toma uma dimensáo importa nte, porque o poder de difusáo acaba sendo um agravan te da crise.

As organiza<;:óes estáo preparadas para enfrentar crises, principalmente quando a situa<;:áo torna-se grave e exige do admi nistrador decisóes rápidas e estratégicas? Pelos acon tecimentos recentes, mesmo após todos os alertas, podemos inferir que muiras empresas e governos n áo estáo devidamente preparados pa ra enfrentar crises de grandes propor<;:óes. Atrapalham-se ou demoram na tomada de decisáo, cometem er ros graves nas crises mais sérias e náo seguem fundamentos básicos recomendados para situa<;:óes de risco.

O exemplo hoje mais evid e nte pode ser tirado da explosáo e consequente vaza mento de milhóes de litros de pet róleo da plataforma da British Petroleum-BP, no Golfo do México, entre abril le setem bro deste ano. A sucessáo de erros, gafes e disputas com o governo america no agravaram o acidente pelos danos irreparáveis, tanto ao meio ambiente, quanto a imagem da organizayáo. No pedodo mais agudo da crise, a BP perdeu $35 \%$ do valor de mercado, um tambo difícil pa ra qualquer empresa, mesmo a gigante inglesa.

Náo importa a natureza da atividade. As empresas e os governos deviam saber que tao importante quanto gerenciar as crises, é monitorar os riscos da atividade para evi tar situ a<":óes limite. É mais fácil gerenciar e se sair bem na crise, qua ndo a organiza<;:áo se prepara. Mas o tema ainda $\mathrm{n}$ ao faz parte dos progra mas de treinamento e de preven<;:áo dos executivos. Muito menos da área pública. Com raras exce<;:óes, nao existe cultura de preven<;:áo de crise. Co mo em otttros programas, prefere-se a a titude reativa ao invés de a<;:óes proativas, que evi tem prejuízos ou rranstornos graves aos negócios. Essa cultura está presente apenas em al gum as multinacionais, mas passa longe das organ iza<;:óes públicas.

As emp resas de rela<;óes públicas tem procurado se especializa $\mathrm{r}$ no gerenciamento das situ a<;:óes de crise. As agencias de publicidade, de modo geral, nao tem tradi<;:áo na presta<;:áo desse servi<;:0. Falta experien cia e habilidade para dar supor te aos clie ntes nessa hora. Acaba sobrando para as assessorias de comunica<;:áo das própr i as e mpresas, que buscam adq uirir competencias para ajuda $r$ as organiza<;: óes a supera $r$ situa<;:́́es difíceis. O resultado muitas vezes é a improvisa<;:áo, num seto $r$ que exige cada vez $\mathrm{m}$ ais profissionalismo. Isso náo aconcece a penas com pequenas e médias empresas.

Gigantes, do porte de um a BP ou Toyota, co merem erros primários na hora da crise. "A condu<;;áo do vazamento pela BP, de urna perspectiva da gestáo de crise, ficará $\mathrm{n}$ a históri a como u m dos grandes exemplos de como tornar uma sirua<;:áo pior pelas falhas de comunica<;:áo", disse Michael Gordon, do Gr upo Gordon Strategic Co mmuni cations, de Nova York.

Gra ndes organiza<;:óes já col oca ram o gerenci amento de crise na pauta de trein a mento dos executi vos. Mas os programas ainda se limita $\mathrm{m}$ basicamente as rela<;:́́es com a mídi a. Esqu ecem outros públicos decisivos. Nao aprendem a blinda $r$ o negócio, para evitar que a crise afete o "cor business" da empresa. Geralmente a com unica<;:ao é acionada, quando o fa to negativo está consum ado. A co munica<;:áo, ao invés de ser apenas parte da solu<;:áo, passa a ser o ú nico meio de amenizar o problem a. Nessa situa<;:áo, náo dá para fazer milagre. É ainda Michael Gordon, quem afirmou a Reuters, sobre o desastre de gerenciamen to da crise da BP: "é uma combina<;:áo de falha de transparencia, uma falha no discurso direto

1 http://www.reurers.com/article/íd USTR.E65S3J L20100629- Consulra em 20/09120 10 
e urna falha de sensibilidade para com as vmmas. Quando voce está administrando um desastre ambiental desta magnitude, voce náo apenas tem que adm inistrar o problema, mas também administra $r$ todos os stakeholders".2

Gerencia de crise e de risco

É preciso separar gestao de crise e gestáo de risco. E entender o papel da com unicac;:áo na crise. O profissional de comun icac;:áo náo gerencia a crise. Essa deve ser tarefa de um grupo específico, geralmente um time profissional, que forma o comité de crise. A comunicac;:áo é um dos mais importantes pilares da gerencia de crise, nao há dúvida. Se náo houver trabalh o conjunto, o esforc;::o de um e de outros nao será suficiente para administrar o problema. A comunicac;:áo sozi nha náo resolve. Quando urn a crise se abate sobre a o rganizac;:áo, ela transcende a comunicac;:áo. Esta vai auxilia $r$ a empresa a ame nizar a repercussáo da crise, a percepc;:áo que a sociedade terá do faro negativo, se mpre um agravante nessas situac;:óes. Afina!, a comunicac;:áo é a guardia da marca, da imagem.

As crises nao avisam onde váo acontecer: pode se $\mathrm{r}$ na área financeira, seguranc;:a, operac;:óes, na gestáo da emp resa. A maioria decorre de atos de gestáo. Pesquisas cond uzidas nos últimos dez anos pelo Ins titute for Crises Management ${ }^{3}$, dos Estados Unidos, mostram que cerca de $70 \%$ das grandes crises empresariais no mundo, náo im porta a dimensáo, tém origem em erros de gestáo. As empresas enfrentam situac;:óes difíceis decor rentes de atos de diretoria ou decisóes adm inistrati vas er radas, preci pitadas ou mal intencionadas.

O gerente de crise, junto com o com ité, deve ser um executivo com autonomía para tomar decisóes, como respaldo da cú pu la da organizac;:áo. A lideranc;::a também é fator decisivo na crise. Náo existe admi nist rac;:áo de crise, sem comando e comprometimento da alta direc;:áo. "Planos de crise tem gra nde probabili dade de falhar sem a integral participac;:áo do board

2 http://www.remers.com/anic le/id USTRE65S3JL20100629- Consulta em 20/09/2010

$3 \mathrm{hrtp} / / \mathrm{www}$. crisis experts.com/ reports_main.htm- Consulta em 15/09/2010. da organizac;:áo" (AUGUSTI NE: 2009). Nesse grupo, certamen te um dos papéis fundamenrais, mas náo único, é o do profissional de comunicac;:áo. Junto com um coo rdenador, mais as áreas jurídica, de seguranc;::a e inteligencia, auditoria, recursos humanos e do diretor responsável pelo setor onde ocorre a crise, eles compóem o com ité ou gabinete de crise. Poucas pessoas. Mas decisivas, com autonomía e autoridade.

Do $t$ rabalho do profissional de com unicac;:áo depende a versáo de como a crise vai chegar a sociedade. Voce pode ter excelentes profissionais de comunicac;:áo, estratégia perfeita para neutralizar notícias negativas e até um bom relacionamento com a mídia. Mas se o núcleo da crise náo for conduzido com eficiencia, transparencia e profissionalismo, esse trabalho na comunicac;:áo náo adianta. A empresa tem que fazer s ua parte da melhor maneira possível, adm in istrar todos os passivos gerados por urna crise. Entáo, a comu nicac;:áo entra fazendo aquilo que sabe, principalme nte aparando as relac;:óes com os meios de comunicac;:áo, afinando o discurso dos executivos, avaliando cenários e monitorando a versáo da crise. A zona de sombra entre gerenciar a comunicac;:áo e administrar a crise acaba levando os executivos a esperar que a com unicac;:áo sozinha resolva o problema da empresa. Nada mais errado.

Gestáo de crises tem a ver com poder económico? Talvez. Os americanos, por exemplo, tem mecanismos de gerenciamento de crise bem estruturados. Estudam o que acontece comas empresas concorrentes e acabam aprendendo com os e rros dos outros. Ex istem muitas organizac;:óes especializadas em monitorar crises empresariais, prestar consultoria, difundir preceitos e e nsinar a evitá-las ou, pelo menos, a explicá-las. Eles chegam ao requinte de segmentar por tema. Hoje, já existem empresas de gerenciamento de crises especializadas e exclusivas para as áreas educacional, hospitalar, militar, fi nancei ra, por exemplo. Exemplos nao faltam. Além do recence acidente ambiental, outro tipo de crise que teima em atingir as escoJas a mericanas e, mais recentemente, também as da Europa sao atentados violentos contra a vida.

Quem náo lembra do triste episódio ocorrido na Universidade Virginia Tech, em 2007, quando 32 estudantes e professores foram morros por um colega. Em 2007 e 2008, dois atentados semelhantes ocorreram 
na Finl andi a, apesar de o mesmo pro tagonista te $\mathrm{r}$ pastado ostensiva mente no YouTube as ameac;:as contra os colegas. Nesses episódios, oco rre ram er ros primá rios de gestáo de crise. A comec;:ar pela fa lta de prevenc;:áo das ameac;:as e monimramento dos riscos que poderiam ter minimizado a tragédia.

Com toda a experiencia dos países mais desen volvidos e m gestáo de risco, ainda assim, até profissionais expe rientes sao surpreendidos e com etem er ros graves na avaliac;;:ao de crises potenci ais. Conflitos raciais, greves, protestos e outros tipos de crise que afetam govern os; acidentes ecológicos, crises financeiras ou na área de saúde sao o utros remas de al to risco para a imagem. Como sao fatos que afetam as organizac;óes de qu al quer ramo, a administrac;:áo de crises se consoli dou como urna competen cia necessáriae imprescindível no currículum dos CEO.

\section{Experiencia latinoamericana}

$\mathrm{Na}$ América Latina, ainda sao poucas as consu ltorías especializadas nessa a ti vidade. Por isso, busca-se soluc;:́ées i nternas. Há algumas empresas, como a brasileira Petrobras, que, a pós eventos n egativos para a imagem, no passado, criou gerencia de crise mui ro bem esrrururada e investe bas tante nesse tema. Vazamentos de pe tróleo, além do grave acidente com a Pl ataforma P36, em 2002, leva ram a empresa brasil eira a profissionali zar a ges tao de crises. Ho je, prova velmente é urn a das orga nizac;::́es petrolíferas com a melhor est rurura para gerenciar crises, tanto no a mbito operacional, quanto de comunicac;:áo, no Brasil e no exterior.

Na Améri ca do Norte e Europa, da década de 80 para cá, a prática da prevenc;:áo, com investimentos e qu al ificac;:áo para evita $\mathrm{r}$ si tuac;:óes de risco, já é comum. Mas na América Latina nao há a inda urna tradic"áo nesse particular. Apesar das experien cias negativas do passado, a gestáo de crise ainda deixa a desejar. O governo brasileiro, por exemplo, tem extrema dificuldade de administrar a té crises ban ais. Fa tos negativos, com e nvol vimento de a utoridades ou funcionários, que a contecem nos ministérios e a té dentro do Pal ácio do Planalto (Sede do governo), as autoridades leva m dias para resolver. Nestes oito a n os do Governo Lula, já aconteceram pelo menos tres escandalas envolvendo ministros na Casa Civil, ou seja, a antessala do Gabinete do presidence, atribuindo-se mais a mídia o impacto negativo do que aos erros das autoridades envolvidas. Essa é urna maneira equi vocada e cómoda de empurra r a crise para debaixo do tapete. Errada, porta nto.

O mesmo acontece com al gumas multin acionais que, nos últimos anos, chegaram a América Latina, como as empresas telefónicas, montadoras de automóveis, concessio ná ri as de tv a cabo e bancos. Além de cometerem erras graves de atendimento, gerenciam erradamente situac;:óes de crise, com prejuízos aos usuários. De mora m a tomar decisóes; porta-vozes equi vocados, declarac;:óes in tempestivas, evasivas e tentativas ma is de esconder do que esclarecer. Sucessivos erros acaba m afetando o negócio.

Gerenciamento de crise que comec:;a mal, dificilmente acaba bem. O sucesso ou fracasso depende das ac;;:́es tomadas n as primeiras 24 horas. Qua ndo a administrac,;ao da crise escorrega, o resultado imediato bate na com unicac;:ao. A o pini áo públi ca náo fica confortável com as explicac;;óes e a mfdia acaba explorando e agrava ndo a crise. A simples publicac;:áo de matéria paga, dize ndo que está rudo sob controle, é urna medida apenas para cum prir um ritual ou dar satisfac;:;ao aos acionistas e empregados. Do ponto de vista da comunicac;:áo, é inócua. O que a sociedade quer é informac;::ao clara, objetiva, com argumentos consistentes de defesa ou reparac;:áo. E isso a imprensa, se perceber seriedade, vai publica r.

O aprimorame nto dos meca nis mos de prevenc;:áo deverá ser o próxim o passo a ava nc,:a $\mathbf{r}$ n a gestao de crise. Ho je, a enfase está na gestao de risco, urna vez que parte-se da pre missa de que a ma io ria das crises é previsível. Jon athan Bernstein, especialista em gestáo de crises nos EVA, assegura que nos seus 25 a nos de atividades, pel a ex perienci a adquirida, 95\% das crises poderia $\mathrm{m}$ ser previstas. ${ }^{4} \mathrm{Ou}$ seja, elas dao sinais que iráo acontecer. Por isso, as emp resas tem como se preparar.

Crises afetam imagem e resultados

É muito difícil para a comuni cac;:ao sensibiliza $r$ os execu tivos sobre o desgaste de image m numa crise. Aferic;:ao de imagem para muitos

$4 \mathrm{hrrp} / / / \mathrm{ww} w$. bernstei ncris is managemen $\mathrm{r} . \mathrm{com} / \mathrm{n}$ i/cris is-manager-090702.h rml Consul raem 24/09110 
administradores ainda é algo intangível, difícil de medir e en tender. Em fun<i:áo disso, nao se impressionam sobre a importancia da reputa<;:áo, num mercado em que passar credibilidade, muitas vezes, pode ser mais importante do que vender produtos.

Pela forma<i:áo academica e utilitária de muitos gestores, preocupamse com os gráficos do mercado. Só qua ndo o efeito da crise atinge os resultados, as vendas caem e os clientes se afastam, aí eles percebem o prejuízo de ocorrencias mal administradas. Existem pesquisas mostrando que há urna rela<;:áo direta entre a boa imagem da organiza<i:áo e a cota<i:áo das a<i:óes nas bolsas de valores. Em média, ativos intan gí veis representam cerca de $65 \%$ do valor de mercado da maioria das empresas públicas. Eé por aí que a comunica〈iáo deve sensibilizar os administradores.

Pesquisas quantitativas feítas no Brasil com empresár ios, jornalistas e o u tros formadores de opiniáo, para medir a percep<;:áo das notícias negativas, mostraram que elas tem um im pacto quatro vezes maior na constr u<:áo da imagem do que o das info rm a<i:óes positivas. Significa que o peso da cober tura de crise na imagem da organiza<j:áo é extremamente negativo para a reputa<j:áo e para os negócios. A avalia<i:áo de imagem passa, pois, a ser ins trumento de rrabalho. Com a a juda de boas consultorí as, já é possível monitorar dia-a-dia a imagem da organiza<i:áo. E isso pode balizar decisóes estratégicas sobre o negócio.

O Brasil enfrentou e m 2006 e 2007, a pós dois graves acidentes aéreos, um gargalo no transporte aéreo, que atrasou vóos e paralisou aeroportos. Os brasileiros convencionaram cha mar o episódio de "apagáo aéreo". Certamente as empresas aéreas fizeram pesquisas após os acidentes e o a pagáo. Algum as consultorías calculara m o prejuízo desse apagáo para as companhias de avia<:áo brasileiras em bilhóes de reais, levando em conta, nao só o prejuízo e a queda do valor de mercado, mas toda a perda na cadeia produtiva decorre nte de atrasos, cancelamentos de vóos, mercadorias nao ent regues e negócios cancelados.

Os Correios, empresa pública brasileira, detenta ra do quase monopólio no transporte de correspondencia e malotes, com urna tradi<;:áo centenária, enfrentou em 2005 urna grave crise de imagem. Oiretoria e funcionários foram envolvidos em denúncias de corr up<;:áo. Urna Comissáo Parlamentar de Inquéri to-CPI, n o Congresso Nacional, acabou descobrindo pagamento a parla mentares em troca de votos no Con gresso. Foi um dos piares momentos na história dos Cor rei os brasileiros. Apenas em urna diretoria, segundo informa $<$ :óes de ge re ntes, o prejuízo com negócios $n$ ao rea lizados teria chegado a $\mathrm{R} \$ 140$ milhóes. Crise, portanto significa prejuízo.

A empresa moderna nao pode viver sem medir resultados. 1sso vale tanto para a área financeira quanto para a de com unica<j:áo. As percep<;:óes que a sociedade e os potenciais clie $\mathrm{n}$ tes tem das empresas e dos governos iráo balizar os negócios, os investimentos, as decisóes futuras. Para ci tar u m exemplo. Ninguém discordada for<:,a da m arca Parmalat. Os negócios da empresa, no Brasil, ai nda hoje estáo sensibilizados pelos efei tos da crise acorrida na Itália e que acabou a tingindo a marca no exterior. Anos depois da crise, a fili al bras ileira tem dific uldade de obter capi tal de giro, devolvendo fábricas que comprou e atrasando pagamentos a fornecedores.

Isso vale também para marcas forres e que se eva pora ram em fun $<_{i}$ :áo das crises, co mo Vari g, Mesbla, TW A, Enrom, WorldCom, Art hur Andersen, Pan Am, Union Carbide e tantas outras. Acion is tas, fornecedores, clientes e o mercado em geral se impress ionam com desempenho, principalm ente quando os números afetam os balans:os das compa nhias. Além disso, a chegada de muitas multinacionais trouxe u rna cultura, pouco afeita ao brasi leiro, de cobran $<, a$ de resul tados.

O papel da mídia nas crises

A mídia cumpre um papel i mportante na cobertura das crises. Como a imprensa gosta do conflito, do contraditó rio, crises sao pautas excelentes. O problema é quando a imprensa extrapola e maximiza a crise, mui tas vezes editorializando a pauta. Du rante crises $\mathrm{m}$ a is graves, envolvendo o presiden te Lul a da Silva, do Brasil, jornais e revistas de gra nde circula<;:áo produzira $\mathrm{m}$ algum as manchetes, com base em análises $\mathrm{s}$ uperfici ais, quase sempre pautadas por parla mentares da oposi< ;:áo ou desafetos políticos.

Outras reponagens decorreram de vazamentos de documentos, que sao repassados ao Congresso Nacional, $\mathrm{m}$ as protegidos sob sigilo bancário. Os senadores e depurados ap roveiram-se das Com issóes Parlamen tares de Inquérito- $\mathrm{CP}$ is pa ra transformá-las em vi trines. Muitas vezes, pautam a 
mídi a combase em factóides. Em tempos de jornal ismo onl ine, o jornalista sai correndo para produzir cham adas e matérias em blogs, agencias de notícias, rádios e canais de TV, sem que o tema esreja de vidamente apurado. Em muitos casos, até mesmo sem ouvir o outrolado.

Segundo um edi tor de revista de circulac;:ao nacional, em Brasília, as crises de govern o estimul am urna gincana sem a nal entre as revistas de grande circulac;:ao, para ver quem sai na frente com o furo. Resultado: algum as manchetes acabam sem substa ncia para se sustentar. Oo is dias depois, ninguém $\mathrm{m}$ ais fala do ass unro, dia $\mathrm{n}$ te dos des mentidos, das inco nsistencias e até de erros facruais.

Essa ansiedade pelo furo ajudo u a derr ubar, em 2006, o entao todo poderoso Mi nistro da Fazenda do Brasil, An to nio Palocci. A revista brasil eira Época, na corrida pelo furo, recebeu a in form ac;:an de que havia depósitos s uspei tos na con ta de um caseiro, que vinha den unciando o minist ro. A revista, precipitadame nte, embarcou no logro e jogou a infor $\mathrm{mac} ;:$ an on line, levantando suspeitas sobre os depósitos, que poderiam ter vindo de pessoas ligadas a oposic;; ao ao governo Lula. Com isso, arranhou u m valor fundamen tal da i mprensa: credibilidade. Isto porq ue o depósito na conra do casei ro nao tinha qualquer relac;;a com as den únci as, como $\mathrm{s}$ up unh a o governo. Os depósitos suspeitos, co m provados depo is, provin ham do pa i do caseiro, que vivía no Nordeste do país. Era um segredo de famíli a que veio a tona para desmenti $\mathrm{r}$ a matér ia apressada da revista.

Se as em presas ai nda patinam em procedimentos básicos nas crises, ai mprensa, como se ve, também escorrega. Matérias a pressadas, como cost u mam ser as relacionadas a crises, acabam er radas ou cometem in justic,:as. É preciso ap urar melhor e só publicar qua ndo o assun to esti ver $\mathrm{m}$ ais claro. Algu ns acusados se vale m dessa fragil idade para se defender e ficar impun es. As vezes, o foco da notícia publ icada está errado, nao ficou claro e confunde mais do que informa.

Os governos com viés di tatorial gosram de culpar a mídia por suas crises. Dizem que a imprensa aposta no quanto pior melhor. Que faz o jogo da oposic;:áo. Sáo autoridades que n ao admirem o conrraditório. Sonham em manietar a im prensa, porq ue a consideram u m em pecilho as ati vidades nem sempre éticas do próprio governo.
A im prensa é importante $\mathrm{n}$ as crises para rrazer a opi niáo $\mathrm{p}$ ública assun tos que, as vezes, sáo apu rados em gabinetes, a ud itor ías internas, processos si gilosos e náo chegam a sociedade. A im p rensa, mu iras vezes, con tribuí com os órgáos fiscal izadores e aré o Congresso Nacion al, porque t raza tona assu ntos que a sociedade náo conhece, mas tem a obrigac;:áo de saber. Pel o m en os, rem-se a vanragem do debate, do cont raditório, o que pa ra a democracia é mui to bom. A i m pre nsa só náo pode, e por vezes o faz, se tra nsformar em pro motor e jui $\mathrm{z}$, a vocando o pa pel eq uivocado de acusar e julgar quemé acusado. Em tempos de jornalismo on li ne, busca do furo, proli ferac;,áo de blogs e redes socia is é u m pe rigo a divulgac;:áo de noticias sem a devida apu rac;:áo. Na pressa, corre-se o risco de disrorcer a informac;:áo em beneficio do furo. Ou, pior, cometer injusric;;as diffceis de ser consertadas.

A imprensa também tem dificu ldades para cobrir crises. Algum as fontes tenta $\mathrm{m}$ a inda usar a velh a prática de minimizar, te $\mathrm{n}$ tar enganar a opi niáo pú blica. A sociedade at ual evoluiu mu ito. Mesmo n uma pop ulac;:áo de po ucos lei tores e com grandes desn íveis cul t urais, até quem escura rádio ou assiste a TV acaba en te nde ndo e cob rando mais transparencia. O espec tador o u leitor náo engo le qua lquer coisa. Muitas fontes sáo pouco convi n centes para convencer a opi niáo públ ica nas crises. O CEO da BP, dura nte a crise, Tony Hayward, náo transm itía seguranc;: a e ram po uco sinceridade nas suas declarac;: óes. Ele sempre queria esconder evidencias que as imagens onl ine mostravam ao vivo e acores.

Embora nao se possa julgar a mídi a pela busca do furo, exisrem m ui tos inreresses em jogo nas crises. Pode haver in tenc;:áo de direcionar a pa uta, m aximizando algu ns re mas e minimizando ourros. Época de eleic;:óes é um bo m exemplo. Tal vez o p ro blema nao esteja na dimensao da n orícia pu blicada, mas na pa uta. Nas crises, a imprensa pode ser mais pa utada pel as fontes ou grupos de pressao - o que incl uí até mesmo órgáos fiscalizadores- do que pelo inreresse público. Mui ras pautas sao cond uzidas pelas fonres ou lobbi es e a im prensa ent ra no jogo da ndo urna dimensao desproporciona! a cerros temas. Deve-se ter cuidado, po rque pode haver interesses políticos ou económ icos por rrás das grandes crises.

As empresas, cabe enfrent ar o problema e respeitar as pri ncipais premissas da gestao de crise: agir rápido, disposic;:ao para infor mar rudo, 
nao po upar ninguém, escolher um bom por ta-voz e dar a tenc;:ao as pessoas afetadas.

ClJ

\section{Conclusao}

Gestao de crise passa a ser, porta nto, urn a co mpeten cia exigida hoje dos principais gestores empresariais. O pitar da comunicac;:áo, embora decisivo nos mom entos cruciais da organizac;:áo, náo basta para resolver crises de imagem. A experie ncia da equipe de relac;:óes públicas faz urna grande diferenc,::a. Mas a gestáo de crise compete nte, principalmente os casos mais complicados, exige a constituic;:áo de um gabinete de críse. "Há evidencias de que o píor momento para iniciar um relacionamento com a imprensa ou aprender a lidar com a crise é dura nte urna crise" 5 .

Portanto, para a área de co municac;:áo as crises sáo um desafio. Um plano de gerenciamento de crises nao pode ser construído na hora da crise. Mas, com antecedencia, baseado na prevenc;:ao, no levantamento das vulnerabilidades e num relacionamento duradouro com a mídia. É ta mbém um te mpo de afirmac;:;ao. A impor tancia da comuni cac;:áo numa o rga nizac;:ao é sempre lembrada e medida pelo desempenho em situac;:óes de crise. Quando a situ ac;,aa está sob controle, é m ais fácil conduzir as ac;:;́es de comunicac;:ao, até porque os executivos estao menos estressados, nao há temas polémicos em pauta, enfim, a comunícac;:ao fluí de forma natural. Na crise, há um stress, quando nao o panico, que absolutamente agrava o problema e náo é recomendado nesses momentos.

O estopim de urna crise pode se r o momento em que a orga nizac; ao enfrenta um fato negati vo grave, com potencial para desestabil izar a diretorí a e ameac;:ar o negócio ou as atividades. Nessa hora, compete a área de comunicac;:;ao mo ni to rar e estabelecer todas as pontes entre os executivos- que estao conduzindo a crise - com a imprensa, que vai di vulgar a versáo da crise. Muíro provavelmente, o que as pessoas saberáo sobre s ua críse é o que a mídia irá publicar. Desse trabalho, vai depender a perce pc;:ao positiva ou negativa da socied ade. Esse episódio pode ser urna

5 ANTHON!SSEN, Peter. Crisis communica tion: Practica) PR strategies for reputation managcment and company survival. pp. 146. oportunidade de afirmac;;ao, de demonstrar respeíto pelo consumidor, e até mesmo urna boa ocasiao para fortalecer a marca.

\section{Referencias}

Antho nissen, Peter. (2008). Crisis communication: Practica! PR strategies for reputation management and company survival. London and Phil adelphia: Kogan Page.

Augustine, Norman. (2009). Como lidar com as crises. Os segredos para prevenir e solucionar situaróes críticas. Rio de Janei ro: Ed. Elsevier.

Caponigro, Jeffrey R. (2000). The crisisconselou;: Chicago: Contemporary Books.

Duarte. Jorge. (2010). Assessoria de Imprensa e Relacionamento coma mídia. Teoría e Técnica. 3. ed. Sao Paulo: Atlas.

Forni, J. J. (2007). Comunicac;:;ao em tempos de crise. Entre vista a Revista Organicom - Revista Brasileira de comunicaráo OJganizacionaLe ReLaróes Públicas- Ano 4- n 6-1o semestre de 2007. Sao Paulo: ECNUSP, pp. 196 a 211.

Lucas, Lucia ne. (2007). (Org.) Media Training. Como agregar valor ao negócio melhorando a relaráo com a imprensa. Sao Paulo: Summus Editorial,

Neves, Roberto de Cast ro. (2002). Grises Empresariais com a opiniáo pública. Rio de Janeiro: Mauad.

Nogueíra, Nemércio. (1999). Media Training.Sao Paulo: Cultura Editores Associados.

Rosa. Mário. A (2006). Reputaráo na velocidade do pensamento. Sáo Paulo: Gerac::ao Edito rial.

Susskind, Lawerence \& Field, Patríck. (1997). Em crise com a opiniáo pública. Sáo Paulo: Futura.

Thompson, ].B. (2002). O escandalo político- poder e visibilidade na era da mídia. Petrópolis: Vozes. 
Viana, Francisco et al. (2008). A surdez das emp resas - Como ouvir a sociedade e evi tar crises. Sao Paulo: Lazuli Editora: Companhia Editora Nacional.

Organicom- Revista Brasileira de Comunica ao Organizacional e Relac;: :́es

- Públicas- Ano $4-n^{\circ}$ 6- 1o semest re de 2007. Sao Paulo: ECNUSP,

2007.

Internet

www.comunl cacaoecrise.com

ơ www.jforni.jor.br

http:/ /www. bernsteincrisismanagement.com/

http:1/www.crisisexperts.com/ reports_main.htm

http://www.reuters.com/arricle/idUSTRE65S3JL20100629 